\title{
Vehicle Selection for BRT: Issues and Options
}

\author{
Samuel L. Zimmerman, DMJM+HARRIS \\ Herbert Levinson, Transportation Consultant
} \begin{abstract}
role in achieving measurable performance success.
1. Capacity, External Dimensions

2. Internal Layout

3. Doors

4. Floor Height

5. Propulsion Systems

6. Vehicle Guidance

7. Aesthetics, Identity and Branding
\end{abstract}

Abstract

Bus rapid transit (BRT) is a flexible, high performance rapid transit mode that combines facilities, equipment, service and intelligent transportation system (ITS) elements into a permanently integrated system with a quality image and unique identity. Vehicles are an extremely important component of BRT systems, because they not only contribute significantly to BRT's image and identity, but also play a strong

Vehicle-related planning and design issues confront BRT planners in seven basic areas:

This paper draws heavily on 26 case studies documented in TCRP Project A-23 (Levinson, Zimmerman, et al. 2003). It also reflects experience from newer BRT 
systems and concludes with a series of general principles and guidelines for vehicle design, selection, and use in BRT applications.

\section{Introduction}

BRT is a flexible, high performance, rapid transit mode that combines facility, equipment, service and ITS elements into a permanently integrated system with a quality image and unique identity. Its constituent elements include:

1. Running ways

2. Stops, stations and terminals

3. Vehicles

4. Services

5. Intelligent transportation systems

6. Fare collection

BRT must be planned as an integrated system ideally suited for the markets served and the application's physical environment. Having a quality image and a unique identity distinct from the rest of the transit (i.e., local bus) system are also important BRT attributes.

Vehicles may be the most important element to user and non-user perceptions of a BRT system's quality. Vehicles also play a strong role in determining real performance in terms of speed, reliability, and cost. They are critical from the perspective of customers, the community as a whole, and the operating entity for a number of reasons. First, vehicles have a strong effect on every aspect of measurable system performance.

- Propulsion systems impact revenue service times (thus, ridership and revenue), emissions (air pollutant and noise) and operating and maintenance (OM) costs.

- Seating, floor height, floor plan, and door configurations impact stop dwell times, hence, revenue service times and reliability.

- Physical size, aisle width, number of doors and their width and position, and seating numbers and configuration are important determinants of BRT system capacity. 
Second, since potential new transit customers as well as existing ones are exposed to BRT vehicles, their design impacts community and customer perceptions of the quality of the entire system. This perception is primarily visual and aesthetic, but it also relates to impacts such as noise and air emissions. Although not as important as time and cost in effecting mode choice, image and brand influence the willingness of new customers to try BRT. This willingness to ride transit translates into additional ridership, revenue and other related benefits, as do performance factors such as travel time and reliability.

One of the major products of TCRP Project A-23 (Levinson, Zimmerman, et al. 2003) was the documentation of 26 case studies of BRT systems around the world and the results of their assessments into a number of summary observations. The synthesis showed that the proliferation of BRT systems has accelerated the trend toward more rubber-tired transit vehicle specialization, away from the one-sizefits-all (i.e., 40-foot [ 12 meter]) bus to perform all surface transit functions. More attention is being paid to the nature of the markets being served, service offered, and customer and non-customer perception of vehicle quality.

The discussion below provides planners with information that can help them make better vehicle choices. It summarizes observations relating to BRT vehicles from the case studies and other, more recent BRT applications, as well as the TCRP BRT guidelines. It is organized around seven basic themes:

1. Capacity, External Dimensions

2. Internal Layout

3. Doors

4. Floor Height

5. Propulsion Systems

6. Guidance

7. Aesthetics, Identity and Branding

\section{Capacity and External Dimensions}

In nearly all of the 26 case studies, demand was heavy, ranging up to 20,000 or more passengers per hour. That utilization of high capacity (e.g., articulated buses) vehicles with a total capacity (standing + seated) of at least 65 places was essential for either system capacity and/or OM cost reasons. In the case of Los Angeles 
MTA's MetroRapidBus and Boston MBTA's Silver Line, BRT services were initiated with 40-foot (12 meter) vehicles, because long procurement times for larger (60foot [18 meter]) vehicles would have delayed the start of service. Both the LA and Boston systems planned to have 60 -foot vehicles. Eaarly on, demand had nearly outstripped the capacity of the 40 -foot vehicles.

Less than one year after opening, some of the originally planned 60-foot (18 meter), low-floor (Neoplan CNG) vehicles are in operation on the Silver Line. In LA, 60foot low-floor (NABI CNG) vehicles are on order after approximately three years of operation. Several BRT applications in South America and Europe, such as Curitiba and Sao Paulo, Brazil; Nancy, Nice and Caen, France; and Utrecht, Netherlands, operate double articulated vehicles of up to 83 feet ( 25 meters) in length, having a capacity of over 120 total places (at North American loading standards).

Given the high demand nature of many BRT routes and services, transit operators are increasingly using large (over 40-foot) vehicles. The use of unusually large (for the given community) rolling stock adds to BRT's distinct identity, while the extra capacity is helpful for financial, service, and operational efficiencies.

Table 1 shows the external dimensions and capacities (computed for a standee density of 3 standees per square meter) for typical vehicles used in BRT applications.

\section{Table 1. Dimensions and Capacities of Typical U.S. and Canadian} BRT Vehicles

\begin{tabular}{|c|c|c|c|c|c|}
\hline $\begin{array}{l}\text { Length } \\
\text { (Feet) }\end{array}$ & Width & $\begin{array}{c}\text { Floor Height } \\
\text { (Inches) }\end{array}$ & $\begin{array}{c}\text { No. of } \\
\text { Door } \\
\text { Channels }\end{array}$ & $\begin{array}{l}\text { No. of } \\
\text { Seats } \\
\text { (including } \\
\text { seats in } \\
\text { wheelchair } \\
\text { tiedown } \\
\text { areas) }\end{array}$ & $\begin{array}{c}\text { Maximum } \\
\text { Capacity* } \\
\text { seated plus } \\
\text { standing }\end{array}$ \\
\hline $40(12.2 \mathrm{~m})$ & $\begin{array}{c}96-102 \\
(2.45-2.6 \mathrm{~m})\end{array}$ & $\begin{array}{c}13-36 \\
(33-92 \mathrm{Cm})\end{array}$ & $2-5$ & $35-44$ & $50-60$ \\
\hline $45(13.8 \mathrm{~m})$ & $\begin{array}{c}96-102 \\
(2.45-2.6 \mathrm{~m})\end{array}$ & $\begin{array}{c}13-36 \\
(33-92 \mathrm{Cm})\end{array}$ & $2-5$ & $35-52$ & $60-70$ \\
\hline $60(18 \mathrm{~m})$ & $\begin{array}{c}98-102 \\
(2.5-2.6 \mathrm{~m})\end{array}$ & $\begin{array}{c}13-36 \\
(33-92 \mathrm{Cm})\end{array}$ & $4-7$ & $31-65$ & $80-90$ \\
\hline $80(24 \mathrm{~m})$ & $\begin{array}{c}98-102 \\
(2.5-2.6 \mathrm{~m})\end{array}$ & $\begin{array}{c}13-36 \\
(33-92 \mathrm{Cm})\end{array}$ & $7-9$ & $40-70$ & $110-130$ \\
\hline
\end{tabular}

* Computed at Standee density of $3 / \mathrm{mtr}^{2}$

86 


\section{Interior Configuration}

The interior configuration of BRT vehicles influences both passenger capacity and comfort. As noted, the overall capacity of transit systems is influenced by a number of vehicle-related factors, and the interior configuration is one of the more important factors. Easy and rapid passenger boarding, alighting and internal circulation can minimize dwell times. BRT vehicle interior layouts usually include large standing/circulation areas around doors. These aid boarding, alighting, and circulation and can also function as storage areas for baby carriages, bicycles, and wheelchairs, explicitly supporting the mobility needs of the entire community.

Aisle width also influences vehicle capacity. Most conventional low-floor vehicles, even those with a step-up to the rear portion of the vehicle, have a minimum aisle width between the rear wheel wells (second and third axle on articulated vehicles) of about 24 inches $(60 \mathrm{~cm})$. The constraint on aisle width here is the need to accommodate tires and mechanical components; however, some specialized BRT vehicles have independently-suspended single, extra-wide, extra-strength tires with electric motor and gearboxes inside. This allows a wider aisle (maximum width of about 34 inches $(87 \mathrm{~cm})$, permitting easier in-vehicle circulation, lower passenger service and stop dwell times. Irrespective of the running gear utilized, where there is $2+2$ perpendicular seating, the required width of seat banks and the wall of the vehicles will constrain aisle widths to no greater than approximately 24 inches (60 $\mathrm{cm})$.

In rapid turnover markets with relatively short trip lengths (e.g., various European applications, Las Vegas Blvd., Denver Mall), planners have elected to maximize capacity and ease of circulation rather than maximizing the number of seats. Because many transit operators have policies that no customer should have to stand in excess of 20-30 minutes, for longer average trip length markets (e.g., suburb to urban corridors like Pittsburgh's busways and Ottawa's Transitways), interiors are usually configured to maximize seating.

The interior of the Irisbus Civis, used on the Rouen, France TEOR system (Figure 1), illustrates the trade-off between the number of seats, standee area, and aisle width when serving a dense urban corridor with significant passenger turnover. 


\section{Figure 1. Interior, Irisbus Civis Specialized BRT Vehicle, TEOR, Rouen, France}

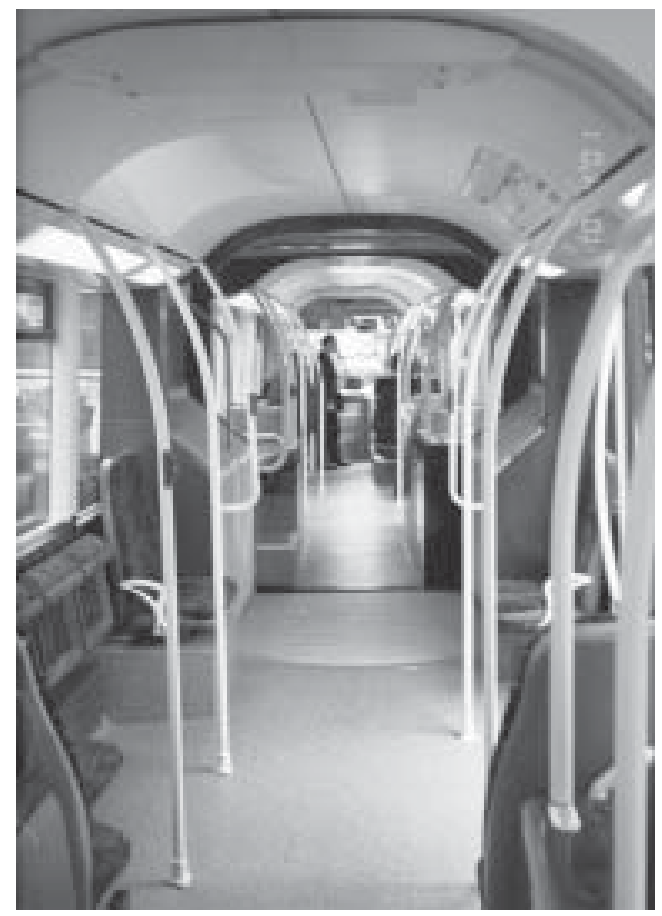

\section{Doors}

\section{Number, Width}

Irrespective of how fares are collected, a large number of wide doors will lower passenger service/stop dwell times. Wider doors provide lower friction than narrow doors and if wide enough, can support either multiple stream boarding or alighting, or simultaneous boarding and alighting. Multiple doors can also result in a better distribution of passengers within the vehicle, thus taking full advantage of available capacity. However, a given vehicle cannot have the maximum number of double stream doors (e.g., up to three on a 40 -foot [ 12 meter] vehicle and up to four on a 60 -foot [ 18 meter] vehicle) and still have the maximum number of seats, since seats are always tied to the outside wall of a vehicle. 
A commonly used rule of thumb for the number of boarding and alighting channels in the U.S. is to have at least one channel per 10 feet of BRT vehicle length for typical radial, suburb - CBD corridors, assuming off-board fare collection. For dense corridors where significant, simultaneous boarding and alighting take place, an even larger number of passenger service streams in the same vehicle length may be warranted. For an express operation where virtually all customers alight in the AM peaks and board in the PM peaks at a limited number of all boarding or all alighting stops, fewer channels may be appropriate.

The Van Hool A300 60-foot (18 meter) articulated bus (Figure 2) operated by RTL from the south shore of the St. Lawrence River to Montreal, illustrates door number and placement for a conventional articulated bus used in a BRT-like service. Note the three double stream doors compared to the two narrower doors normally found on buses of the same size used for local service in the U.S.

\section{Figure 2. Door Arrangement, Van Hool A300 60-Foot Low Floor Articulated Bus, RTL, Longueuil (Montreal), Quebec}

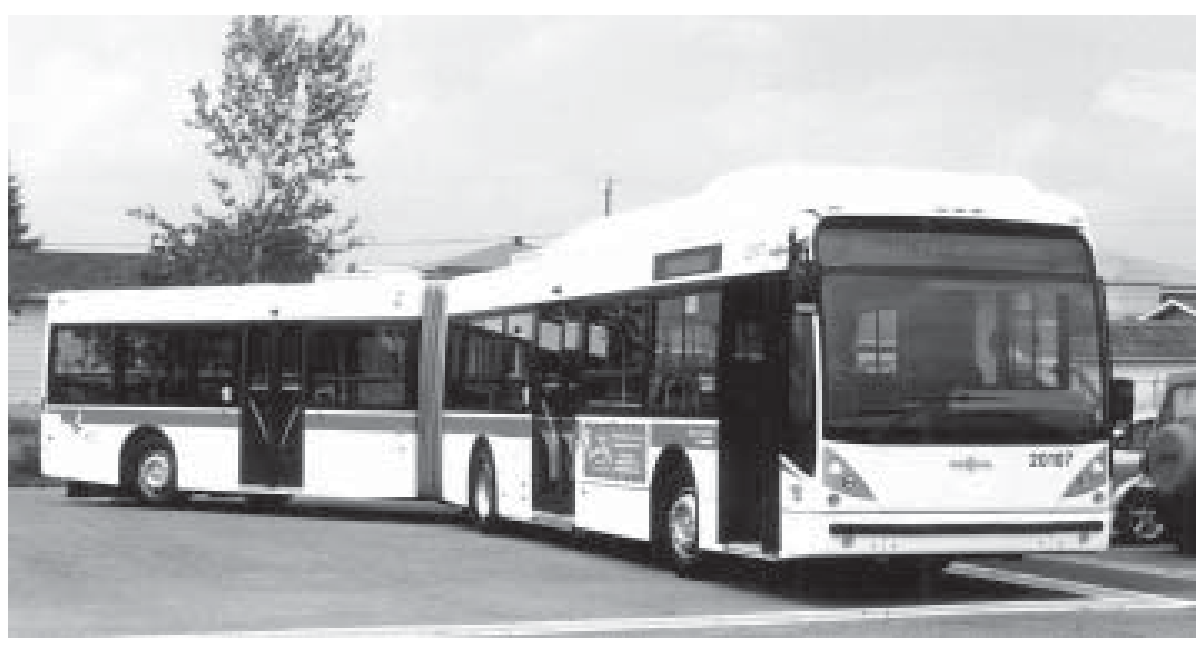




\section{Placement}

The major objective affecting door placement is the need to ensure even passenger loading and unloading across the length of the respective vehicles. Accordingly, doors should be positioned to divide BRT vehicles into sections of roughly equal capacity and circulation distances. A number of recent BRT applications (e.g., Las Vegas and various European and South American systems) have an even distribution of doors and entry/exit streams across vehicle length.

Both conventional buses and specialized vehicles are also available with doors on either the left side (e.g., the Volvo and Mercedes vehicles in Bogota, Colombia and Curitiba, Brazil) or both sides. For years, trolley buses using the tunnel to access Harvard Square Station on the MBTA Red Line had doors on both sides. This is done to allow vehicles to use center platforms exclusively, as for the South American systems, or both the center and side platforms, as planned for a number of U.S. systems such as Cleveland.

\section{Floor Height}

BRT vehicles can have one of three basic floor heights: (1) 100\% low floor; (2) partial low floor (usually about 70\%); and (3) high floor. Low floors (or the low floor portion of partially low-floor vehicles) are typically 11-13 inches from the pavement, while high-floor vehicles are typically from 25 inches to as much as 35 inches above the pavement.

High-floor vehicles have an advantage in BRT applications where absolute maximum carrying and/or seated capacity is necessary, because little or no interior space is consumed by wheel wells, under-floor mechanical equipment, fuel tanks, etc. However, they may have inordinately high boarding and alighting times, unless used in conjunction with some way of assuring no-gap, no-step boarding and alighting. Rapidly deployed door bridges or door flaps have been used for this purpose in high volume BRT applications in South America (Quito, Curitiba, and Bogota). The major disadvantage of high-floor vehicles is that they can usually be used only at stations with high platforms, thereby limiting operating/service flexibility. This issue could be overcome, as has been done on some light rail transit (LRT) systems, by having no-step high platform boarding on one side of the vehicle and stairs to permit boarding from low platform stations on the other side.

One hundred percent low-floor vehicles have the great advantage of low boarding and alighting times and the ability to place a door behind the rear axle. How- 
ever, $100 \%$ low floor designs also typically lose between 4 and 8 seats to wheel well intrusion, even where relatively small wheel and tire sizes are used. Another disadvantage of $100 \%$ low floor designs is that mechanical and electrical equipment and fuel tanks must either be stored inside the vehicle, where they take up space, or put on the roof, where they are difficult to service.

Low profile tires and minimum wheel travel of low floor vehicles may also contribute to poor ride quality. A final disadvantage of $100 \%$ low floor vehicles is the difficulty of packaging conventional mechanical drive trains consisting of an engine, hydraulic-mechanical transmission, connecting drive shafts, a differential, and an axle. One hundred percent low floor designs with this type of drive train can also lose up to four seats or the equivalent standing area merely due to the engine and drive train's intrusion into the vehicle (see Van Hool's A300 series of vehicles). The reason that many low floor specialized BRT vehicles have electric drive trains utilizing hub-electric motors and a single wheel on each side bogies with special wide, high-load limit tires is to avoid propulsion and suspension system packaging difficulties. These features contribute to acquisition cost, weight, and maintenance complexity.

\section{Propulsion Systems}

Low air and noise emission vehicles are extremely desirable for BRT, especially in situations where frequent services converge, such as near or in central business districts (like Pittsburgh, Miami, Brisbane, and Ottawa). With busway volumes often exceeding 100 or more per hour in two directions, community acceptance may depend on use of low air and noise emission vehicles. Low on-board noise levels are also desirable from a customer perspective. Three basic types have been used in BRT applications in North America.

1. Internal combustion, hydraulic-mechanical transmission

2. Dual mode, diesel-electric

3. Internal combustion/electric hybrid

\section{Internal Combustion Engines, Hydraulic-Mechanical Transmissions}

The most common propulsion plant, and the one most likely to be used if a conventional bus is selected for a BRT application, is the internal combustion engine (i.e., clean diesel, CNG spark ignition) driving an automatic hydraulic-mechanical transmission. There have been significant improvements to this type of drive train over the last two decades in response to the need to reduce emissions. 
Electronically controlled, drive-by-wire clean diesel engines will have significantly reduced particulate, hydrocarbon, and $\mathrm{CO}$ emissions from pre-emissions control level by orders of magnitude. Exhaust gas recirculation promises to do the same for NOx emissions.

Available electronically controlled, clean diesel engines and self-cleaning (regenerating) catalytic converters enabled by ultra low-sulphur fuel can have even lower particulate and hydrocarbon emissions than CNG spark ignition engines (but with slightly higher NOx emissions). The catalytic converter/ultra low sulphur fuel combination also contributes to reductions in noxious-smelling hydrogen sulphide gas emissions.

Contemporary spark ignition CNG engine systems have low particulate emissions and can be quieter than current diesel engines, but suffer from higher total system weight, have relatively high operating and maintenance costs, and higher initial capital costs of about $\$ 50,000$ per vehicle. They also have additional fuelling infrastructure costs compared to clean diesel vehicles. Advances in CNG engine and fuel storage technologies may lower CNG vehicle weight and operating costs in the future.

\section{Dual Mode/Dual Power}

Dual mode vehicles essentially combine a full performance electric trolley bus with an internal combustion engine (e.g., diesel, CNG) that is also capable of providing full, stand-alone performance. Dual mode vehicles, therefore, have the advantages of both trolleys and conventional buses with internal combustion engines. Electricity is obtained from overhead contact wires for part of a given route's trajectory, typically in an environmentally sensitive city center or tunnel (like Seattle and Boston). Where an overhead contact system cannot be installed or used, (e.g., a freeway) or is not economical, these vehicles have full performance capabilities using an internal combustion engine.

Dual mode vehicles are attractive for BRT because they can combine the performance, environmental, and permanence advantages of trolleybuses, with the flexibility of conventional buses. The main disadvantages of dual mode vehicles are their greater weight and both initial and ongoing increased costs. Rather than needing to maintain a single internal combustion engine/hydraulic-mechanical transmission, dual mode vehicles usually require more maintenance effort and cost, because they have more components. 


\section{Hybrid Internal Combustion Engine/Electric}

Hybrid vehicles combine an internal combustion engine (e.g., clean diesel, gasoline, CNG-fueled spark ignition, or gas turbine) with a drive system incorporating an electric motor/generator or motor/alternator and an on-board energy storage medium. Contemporary hybrid vehicles can perform significantly better than other vehicles in terms of noise, emissions, fuel consumption and acceleration. While hybrid vehicles are cruising, coasting, braking, or stopped at idle, the internal combustion engine can produce energy for storage, and using the electric motor as a generator/alternator during braking also reduces brake wear and tear. Peak noise levels are reduced, since high engine speeds are not required to provide power for acceleration or to climb hills. Peak requirements are met by stored energy being dumped into the system's motor/generator. The internal combustion engines used in hybrids are also smaller and lighter for the same reason. Air pollution and fuel consumption advantages stem from the more constant load on the internal combustion engine and the ability to tune the engine for peak fuel economy.

M.J. Bradley, Inc. and the University of West Virginia (2001) reported that hybrid vehicles using clean diesel engines with low sulphur fuel have better emissions characteristics than pure CNG engines. Revenue service experience in Seattle with a prototype of the hybrid diesel-electric vehicles they recently purchased also suggests significantly better fuel economy and better acceleration than standard diesel equipment.

\section{Guidance}

Guided vehicles, used in conjunction with stations having platforms at the same height as vehicle floors, can be expected to have boarding and alighting times similar to those on heavy rail and some LRT systems, or approximately 2-3 seconds per person per channel (25-35\% savings), compared to passenger service times for conventional buses or streetcars with steps of 4 or more seconds per passenger per channel.

No-step, no-gap boarding and alighting can also significantly reduce the time it takes for customers carrying packages, having disabilities, and/or with children in strollers to board and alight from BRT vehicles. This, combined with wide aisles, can significantly reduce passenger service times for these customers, thereby improving schedule reliability. Guided vehicles also have advantages in terms of riding comfort and right-of-way width for dedicated transitways. (As previously noted, 
another way to provide no-step boarding is through the use of vehicles with a ramp or bridge deployable at stations). The use of guided vehicles with narrow transitway lane widths has also been cited as a transit-only enforcement tool.

There are two basic types of vehicle guidance systems: mechanical and electronic. The first mechanical guidance system for buses was originally developed for the $\mathrm{O}$ Bahn by Mercedes-Benz (now Evo-Bus). This guidance approach, similar to that utilized on the rubber-tired automated people mover systems found at airports, has been proven in service for many years in Essen, Germany and Adelaide, Australia and in newer, non-O-Bahn applications in a number of British cites, such as Leeds. These systems utilize a pre-cast, concrete track with low vertical side rails or curbs that are contacted by laterally mounted guide wheels that, in turn, are connected to the vehicle steering system's idler arm. More recent guidance systems (as seen in Bombardier's GST and the Translohr BRT vehicles) use a lightduty track embedded in the pavement to provide guidance and to serve as an electric return for the vehicle's electric power system.

O-Bahn type mechanical guidance systems add about $\$ 10-20,000$ USD to the cost of each vehicle (depending on the numbers involved) along with some weight and complexity, while the incremental cost of the curbs necessary to guide the vehicles will depend on whether there are already curbs on the respective running ways. The mechanical systems using curbs provide positive guidance and are safe at relatively high operating speeds (in the case of the O-Bahn, over $60 \mathrm{mph}$ [100 $\mathrm{kph}]$ ).

One important new development in BRT vehicles is the use of advanced electronic technologies (ITS) to provide lateral and even longitudinal vehicle guidance. These systems, as distinct from mechanical guidance technologies, replace physical infrastructure with inexpensive-to-implement magnetic or optical markers on or in the running way. Because of their ease of driver-steered vehicle entry and extraction, the operator can take over at any time and they are compatible with operating plans that feature mixed local and express operations on a single guideway.

There are two types of electronic guidance systems currently in BRT operation: (1) optical, in which a video camera detects the position of a vehicle relative to painted lines on the pavement and steers via a servo motor in the steering mechanism, developed by Siemens and implemented on the Irisbus Civis vehicle; and (2) magnetic, that works essentially the same way as optical, but uses magnets buried in the pavement. The FROG system was implemented on the VL/APTS Phileus. 


\section{Figure 3. Boarding and Alighting Electronically Guided Irisbus Agora and Civis Vehicles, TEOR, Rouen, France}

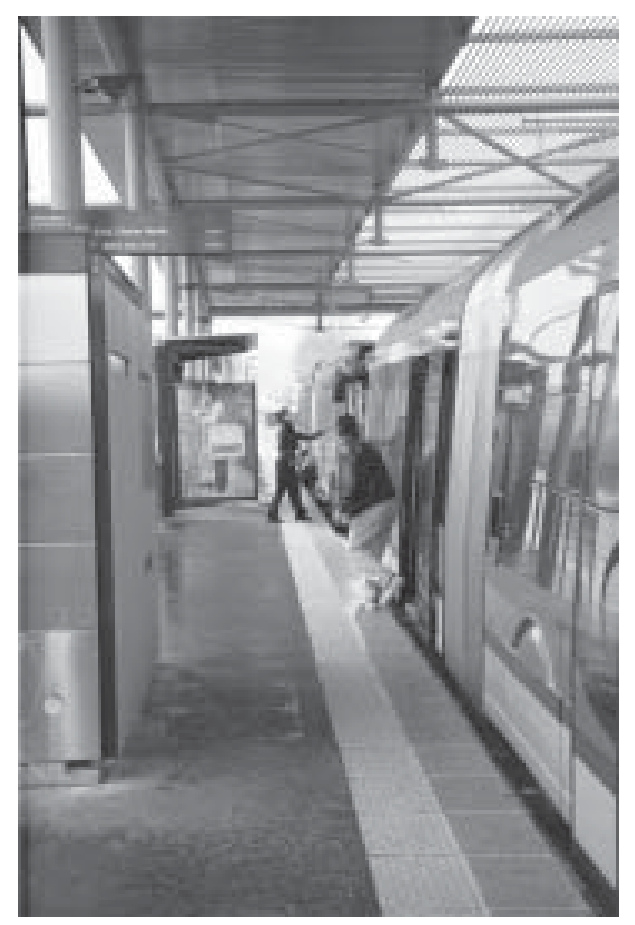

Figure 3 illustrates the docking accuracy possible with electronic guidance systems. Customers easily board and alight from electronically-guided Iris bus Agora and Civis vehicles used on the TEOR System in Rouen, France.

The current incremental costs of the electronics and steering servos necessary to make the ITS- driven guidance systems work are currently in the neighborhood of $\$ 75-100,000$ USD per vehicle. This cost is expected to come down after manufacturers recover research and development costs. Infrastructure costs associated with the systems are modest, since no infrastructure beyond embedded magnets or painted stripes on running way pavements are necessary. A downside of these systems is that they lack the high-speed safety of positive, mechanical guidance.

\section{Aesthetics, Identity and Branding}

A unique vehicle identity for a particular BRT service, achieved through livery (paint schemes, colors, icons) and/or design, not only positions the system vis-à- 
vis the rest of the transit system, emphasizing functional differences, but also tells the large number of infrequent customers (as high as $35-40 \%$ of overall ridership on many rail-based rapid transit systems) where they can board. System branding and identity convey important customer information such as routing and stations served. Vehicle design can complement maps, signs, and other information sources, further enhancing transit ridership.

Compare the exterior look of a specialized BRT Vehicle, the 60-foot articulated Irisbus Civis, to be used for Las Vegas' MAX line (Figure 4), with the conventional bus, an Orion 5, operated by Fairfax County, Virginia in the Dulles Corridor (Figure 5). Both vehicles are attractive and popular in their respective markets. The Fairfax County Connector bus, however, is essentially the same as vehicles serving other routes terminating at the same intermodal transfer facility (West Falls Church MetroRail Station).

\section{Figure 4. Exterior Design, 60-Foot Irisbus Civis Specialized BRT Vehicle, Vegas Blvd. MAX, Las Vegas, Nevada}

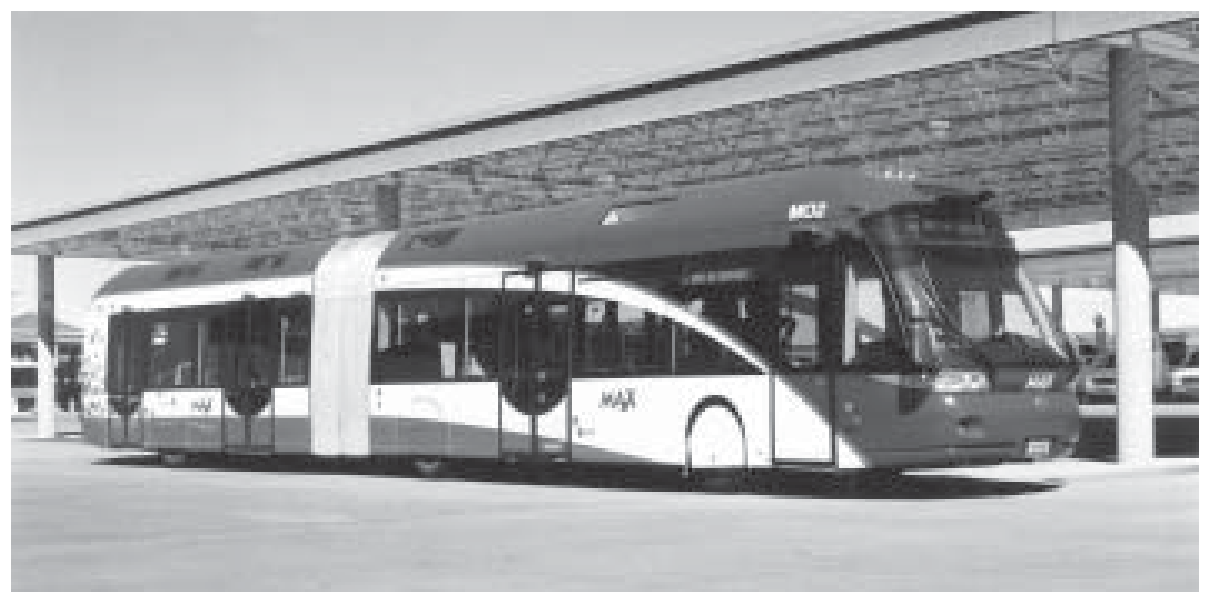

The uniquely styled Civis, on the other hand, is only used in places where it operates for specialized BRT services, sending a visual cue as to stopping locations and routes for the respective rapid services and advertising the BRT system as providing a distinct service. 
Figure 5. Exterior Livery and Design, Orion 5 40-Foot Bus, Fairfax County Connector Dulles Corridor Express Services, Fairfax, County, Virginia

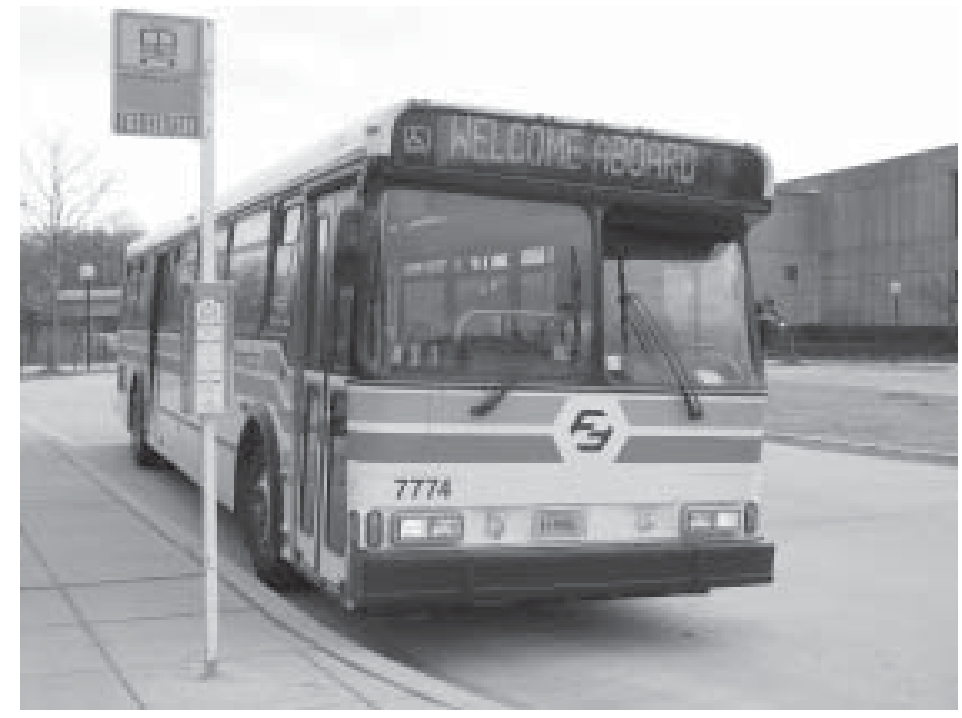

The low floor CNG Neoplan articulated vehicle used on MBTA's Silver Line in Boston (Figure 6) illustrates the creative use of color and livery on conventional equipment to provide a distinct image and identity, matching the color, route name, and map color. Contrast that with the livery of the 40-foot Nova Bus RTS used in regular MBTA local bus service (Figure 7). Such a branded appearance can distinguish a bus in BRT operation from one in local bus service. The vehicle livery and icon or flag should be different from other buses, but match that of BRT stops, stations, and terminals, information signs, graphics, and all printed matter. In this way, it emphasizes that BRT is an integrated system. 
Figure 6. Exterior Livery, Neoplan 60-Foot CNG Articulated Bus, Silver Line, MBTA, Boston, Massachusetts

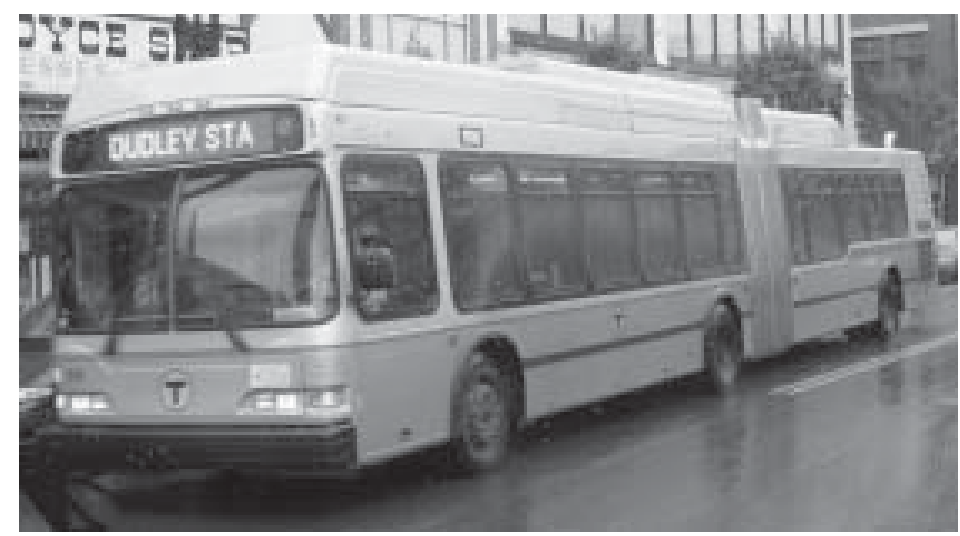

Figure 7. Exterior Livery, Nova Bus RTS 40-Foot Bus, Local Bus Service, MBTA, Boston, Massachusetts

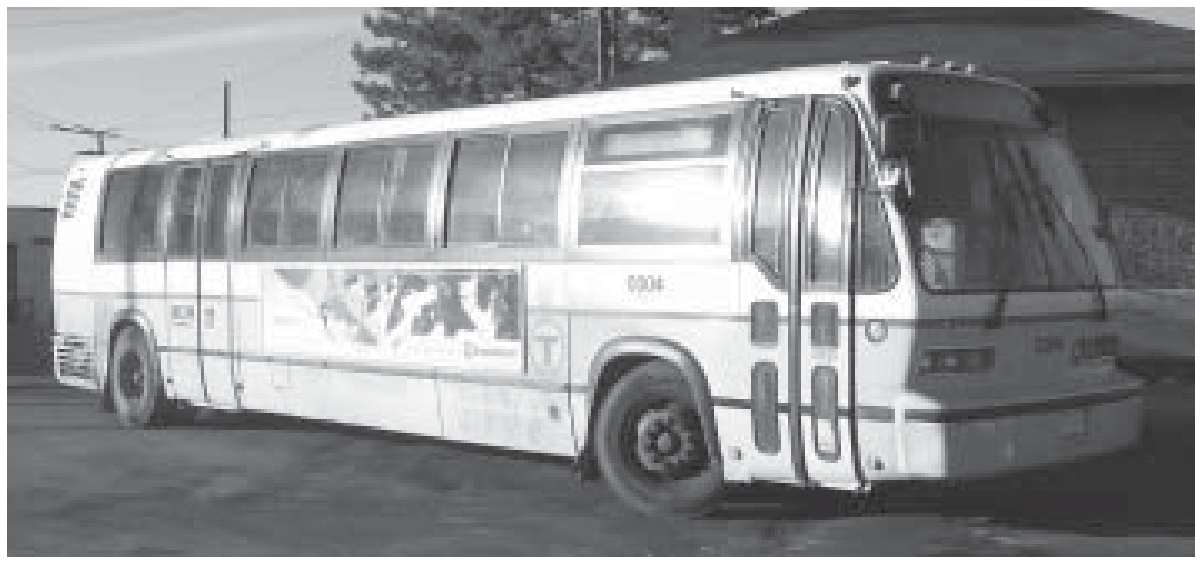

As of 2003, at least five European bus manufacturers (Irisbus, Bombardier, Neoplan, APTS/VDL, and Translohr) have designed and built specialized BRT vehicles with an LRV-like exterior appearance, interior, and other features such as guidance. In Europe and South America, Volvo has BRT vehicle projects under way, while in North America, both New Flyer (Invero) and North American Bus Industries 
(Compobus) have BRT vehicle projects either in production or close to the production of prototypes. Examples of their features include large sizes and distinct shapes (lengths from 45-83 feet [13.8 to 25 meters]), large, panoramic passenger windows, dramatically curved front windscreens, multiple doors, lateral guidance/precision docking, quiet, internal combustion-electric hybrid propulsion, and the option for the driver position to be in the center of the vehicle.

\section{Conclusion}

The importance of vehicles to the overall success of BRT systems cannot be overstated. Vehicle design affects every aspect of system performance and cost, and their appearance, both external and internal, is a key contributor to the system's image, identity and position in the transportation marketplace.

Based on documented experience to date, the following general guidelines should be considered in BRT system planning and project development:

- Vehicles should be planned and ultimately specified as a function of the type of services offered (e.g., local versus express, mixed) and the nature of the markets served (e.g., short non-work non-home related trips versus long home to work trips).

- Vehicles should provide sufficient passenger capacity at comfortable loading standards (i.e., 3 standees per square meter in North America) for anticipated ridership levels and planned service structure and frequencies. Lengths ranging from 40-45 feet (12.2 - 13.75 meters) for single unit vehicles through double articulated (82-foot [ 25 meters]) vehicles are in successful revenue service and can be considered.

- Vehicles should have high passenger appeal, be environmentally friendly, easy and convenient to use, and comfortable. Desirable features include air conditioning, bright lighting, panoramic windows, and real-time passenger information.

- Vehicles should be easy and rapid to board and alight. Low floor heights (i.e., less than 15 inches [ $38 \mathrm{~cm}$ ]) above pavement level) are desirable unless technologies permitting safe and reliable level boarding and alighting (e.g., rapidly deployed ramps/bridges, some type of precision docking mechanism) can be used.

- A sufficient number of doors having sufficient width should be provided, especially where off-board fare collection is provided. Generally, one door 
channel should be provided for each ten feet of vehicle length. Vehicles with doors on either or both sides are available and can enable use of side and/or center platform stations.

- The mix of space devoted to standees and seating will depend on the type of service and nature of the market served (e.g., express versus local). Because a seated passenger occupies more space than a standee, total capacity is higher where the number of seats is lower, all else being equal.

- Wide aisles and sufficient circulation space can lower dwell times and allow for better distribution of passengers, especially to the rear of articulated vehicles.

- Cost-effective bus propulsion systems are available for revenue service that, compared to conventional diesel engine/hydraulic mechanical systems:

- virtually eliminate particulate emissions

- are environmentally friendly in terms of $\mathrm{CO}, \mathrm{HC}$ and $\mathrm{NOx}$ emissions

- are relatively quiet

- get improved fuel economy

- accelerate faster.

- There are mechanical and electronic guidance systems in revenue service that can enable rail-like passenger boarding and alighting convenience and service times at stations, reduce right-of-way requirements, and provide a more comfortable ride than conventional buses.

- Vehicles should be well proven in revenue service before being introduced in large numbers for intense BRT operations. Controlling risk is extremely important in the operation of highly visible services.

- BRT operations with standard vehicles in use on other parts of the respective system are acceptable, as long as distinct livery (color schemes), graphics, icons, and other means are employed to provide a unique identity and image. No special features are required to provide acceptable capacity, levels of service, and passenger attractiveness.

- Even where standard buses are used for BRT operations, consideration should be given to internal layouts and door numbers and configurations consistent with the markets served and service provided. 
- Use of specialized BRT vehicles is often desirable for high volume trunk routes where the operational benefits of the specialized vehicles will offset their incremental costs.

- Cost should be considered on a life cycle basis, as some of the features that add to initial acquisition costs (e.g., guidance, hybrid drives, stainless steel frames, and composite bodies) have the potential to reduce ongoing operating and maintenance costs, increase passenger revenue, and add to vehicle service life.

- It is critical that vehicle planning and design be fully integrated with planning and design for other BRT elements such as running ways, stations, fare collection, and service plans, if the overall system is to achieve its maximum effectiveness and efficiency. 
Journal of Public Transportation, Vol. 7, No. 1, 2004

\section{References}

Levinson, H., S. L. Zimmerman, J. Clinger, S. Rutherford, R. L. Smith, J. Cracknell, and R. Soberman. 2003. TCRP Report 90: Bus Rapid Transit, Volume 1: Case Studies in Rapid Transit. Washington, DC: Transportation Research Board of the National Academies.

Levinson, H., S. L. Zimmerman, J. Clinger, S. Rutherford, R. L. Smith, J. Cracknell, and R. Soberman. 2003a. TCRP Report 90: Bus Rapid Transit, Volume 2: Implementation Guidelines. Washington, DC: Transportation Research Board of the National Academies.

Danaher, A. and P. Ryus. 1999. TCRP Project A-15. Transit Capacity and Quality of Service Manual, $1^{\text {st }}$ Ed. Washington, DC: Transportation Research Board.

Bradley and Associates. 2000. Hybrid Electric Drive Heavy Duty Testing Project Final Emissions Report. Boston, MA: Northeast Advanced Vehicle Coalition, West Virginia University. 


\section{About the Authors}

SAM ZimmeRMAN (sam.zimmerman@dmjmharris.com) is principal of the transportation planning section of DMJM+HARRIS. His 34-year career has focused on rapid transit planning, transit economics and finance, and travel demand forecasting. Mr. Zimmerman has consulted extensively on rapid transit and transportation planning projects, planning procedures, and policy throughout the U.S. and the world, and has written numerous papers. He was co-principal Investigator for the Transportation Research Board's Bus Rapid Transit (BRT) Implementation Guidelines project, and is project manager for the National Transit Institute's BRT Training course.

Herbert Levinson (hslevinson@aol.com) is one of the world's leading experts in traffic engineering, parking, transit planning, and the nexus between transit and traffic operations. He has authored over 150 papers, edited and otherwise contributed to numerous transportation planning and traffic engineering books, taught at major universities such as Yale and New York Polytechnic Institute, performed research for the USDOT, the American Association of Automobile Manufacturers, and the Transportation Research Board (TRB), and has consulted throughout the world. Mr. Levinson is a member of the National Academy of Engineering and serves on the Executive Committee of the Transportation Research Board. He was co-principal investigator for the Transportation Research Board's Bus Rapid Transit Implementation Guidelines project. 